\title{
A Prediction Model of Cutting Force about Ball End Milling for Sculptured Surface
}

\author{
Wenping Mou, ${ }^{1,2}$ Shaowei Zhu, ${ }^{2}$ Menghao Zhu, ${ }^{3}$ Lei Han $\mathbb{D i D}^{3}$ and Lei Jiang $\mathbb{D}^{3}$ \\ ${ }^{1}$ School of Mechanical Engineering, Nanjing University of Aeronautics and Astronautics, Nanjing 210016, China \\ ${ }^{2}$ NC Machining Plant, AVIC Chengdu Aircraft Industrial (group) Co., Ltd, Chengdu 610092, China \\ ${ }^{3}$ Institute of Advanced Design and Manufacturing, School of Mechanical Engineering, Southwest Jiaotong University, \\ Chengdu 610031, China \\ Correspondence should be addressed to Lei Jiang; jianglei0506@163.com
}

Received 26 November 2019; Revised 1 February 2020; Accepted 6 February 2020; Published 11 March 2020

Academic Editor: Xiaoliang Jin

Copyright (c) 2020 Wenping Mou et al. This is an open access article distributed under the Creative Commons Attribution License, which permits unrestricted use, distribution, and reproduction in any medium, provided the original work is properly cited.

\begin{abstract}
Cutting force prediction is very important to optimize machining parameters and monitor machining state. In order to predict cutting force of sculptured surface machining with ball end mill accurately, tool posture, cutting edge, contact state between cutter, and workpiece are studied. Firstly, an instantaneous motion model of ball end mill for sculptured surface is established. The instantaneous milling coordinate system and instantaneous tool coordinate system are defined to describe the position and orientation of tool, and the transformation matrix between coordinate systems is derived. Secondly, by solving three boundaries around engagement of cutter and workpiece, a cutter-workpiece engagement model related to tool posture, milling parameters, and tool path is established. It has good adaptability to the variable tool axis relative to the machining surface. Finally, an algorithm of thickness about an instantaneous undeformed chip is researched, and a prediction model of cutting force is realized with microelement cutting theory. Also, the model is suitable for sculptured surface machining with arbitrary tool posture and feed direction. The accuracy of the proposed prediction model was verified by a series of experiments.
\end{abstract}

\section{Introduction}

Ball end mill is an important milling tool. It has good adaptability to surface machining due to the normal orientation of the spherical contour surface pointing to full space. Using the ball end mill for sculpted surface in $\mathrm{NC}$ machining is simpler than other tools. Therefore, ball end mill is widely used in the machining of aerospace parts, automotive parts, mold parts, and so on. As an important physical parameter, cutting force directly or indirectly affects wear and deformation of tool, machining efficiency, etc. It is an effective indicator for monitoring the machining process [1]. The evident feature of ball end milling for sculptured surface is that the contact condition between the tool and workpiece varies along the tool path. It changes cutterworkpiece engagement (CWE), which defines the area where cutter and workpiece interact to generate cutting force.

The researches for CWE under different cutting conditions are mainly divided into three types: a solid method based on Boolean operation, Z-map method based on discrete elements, and boundary method based on analytical and numerical calculation. The solid method determines the intersection of the cutter and workpiece by Boolean operation. Larue et al. judged intersection point in flank milling by Boolean operation, and cutting angle was modeled in the machining process by the tool site function [2]. Ju et al. proposed a method of discrete boundary representation based on Boolean operation, which was applied to calculate CWE of each blade in ball end milling [3]. Yang proposed a method to solve CWE based on the ACIS model [4]. Gong and Feng established a triangular grid model of cutter and workpiece, and CWE was solved by Boolean operation [5]. Li and Zhu extracted boundary of the contact region based on the intersection of the cutting edge and workpiece, and a general modeling method of CWE was proposed [6]. The solid method can solve the contact area of the cutter and workpiece with high precision. However, it is necessary to update the entities of the 
cutter and workpiece to calculate CWE iteratively, which results in low efficiency.

The Z-Map method determines the intersection of the cutter and workpiece by projecting the cutter and workpiece to plane and discretizing it into a set of points by a given direction (usually $Z$ direction). The $Z$-coordinates of the ray and intersection point between the cutter and workpiece were compared. Kim and Lazoglu et al. calculated the contact area by comparing the Z-Map values during machining $[7,8]$. Dongming et al. used the Z-Map method to verify engage section of cutting edge in machining, and a cutting force model of five-axis machining with ball end mill was established [9]. Wei et al. used logical array to improve the Z-Map method for calculating CWE in sculptured surface machining [10]. As a discrete method, it is contradictory between accuracy and efficiency, which needs to be weighed in different applications.

Based on the analysis of geometric relationship between the cutter and workpiece, the boundary method was proposed to describe CWE by mathematical expression. Gupta et al. proposed an analytical algorithm for CWE of 2.5D milling (the vector of tool axis is fixed.) [11]. Ozturk et al. calculated boundary of CWE for 2.5D milling by ball end mill analytically, and the method was proved to be more efficient than the Z-Map method for CWE $[12,13]$. But, the abovementioned methods are difficult to apply to $3 \mathrm{D}$ milling (the vector of tool axis is varied during machining). Sun and Guo used the Newton iteration method to calculate the boundary of CWE between the cutter and workpiece [14]. Kiswanto et al. established an analytical semifinished tangent region model based on surface profile [15]. Wei et al. discretized sculptured surface into a series of microelement planes. The microelement contact region of $2.5 \mathrm{D}$ milling by ball end mill was constructed, and the contact region of $3 \mathrm{D}$ milling was obtained by rotation transformation $[16,17]$. However, the abovementioned methods are not suitable for sculptured surface machining. Error could be produced when the curvature of surface or cutting depth are large. Zhu et al. proposed a 3D machining contact region model for fillet milling [18]. Three spatial curves are applied to describe the boundary of CWE, but it does not consider the condition about the curved tool path.

By comparing the abovementioned studies, the solid method has the highest accuracy, but its calculation efficiency is low. The Z-Map method has a contradiction between accuracy and efficiency. In actual applications, the size of divided mesh needs to be adjusted according to the priority of accuracy and efficiency, and this adjustment process is usually very tedious. The existing boundary method is well applied in three-axis curved surface machining, but it has limitation in variable axis machining with variable cutting conditions.

CWE is the prerequisite for predicting cutting force. Furthermore, how to calculate the cutting force from CWE is another critical part. The research methods of cutting force modeling are divided into three categories: the theoretical analytic method, finite element (FE) method, and mechanical force method. The theoretical analysis method is based on metal cutting theory, involving multifield coupling effects such as force, heat, strain, and so on. According to the orthogonal cutting model proposed by Merchant, cutting deformation is occurred on a single shear plane only, and shear angle is calculated based on the principle of minimum energy [19]. Lee and Shaffer proposed a slip line theory considering the workpiece material as ideal plastomer, and a cutting force model was established [20]. Oxley et al. researched flow stress of material during cutting and effect of work hardening to complete the cutting force model [21]. Moufki et al. proposed an algorithm for flow stress of bevel cutting based on thermal coupling properties of material [22]. The theoretical model of cutting force is very complicated, and it is necessary to consider many factors, such as material property, cutting temperature, and cutting deformation. It is related to the factors about elastic mechanics, thermodynamics, and tribology. In order to reduce the difficulty of modeling, many simplifications and assumptions are researched, which leads to lower accuracy and smaller application range.

The FE method simulates the distribution of each physical field and deformation process, which could deal with the complex physics coupling effect effectively. At present, some commercial FE softwares (such as ABQUS, ANSYS, and AdvantEdge) have been applied to 2D and 3D milling. However, the FE model is very complicated, and calculation load is huge.

Mechanical method applies cutting coefficient to represent different geometry and physical parameters of cutting. The model is simple, and its adaptability is strong. Lamikiz et al. expressed shear force coefficients as polynomial, and a cutting coefficient identification model was proposed for ball end milling [23]. Lee and Altintaş transferred the parameters that were obtained from orthogonal cutting experiments to classical oblique cutting to predict cutting force of ball end milling [24]. Cao et al. proposed a cutting force model considering the inclination of tool axis [25]. Luo et al. established a cutting force model considering the influence of cutting edge at the apex, and the variation of CWE was analyzed with the feed path and contour of workpiece during machining [26]. Lin et al. calculated the cutting force coefficients of ball end mill based on average single-tooth cutting force [27]. However, the abovementioned research studies are mainly aimed at slab milling with constant cutting conditions.

In this paper, a new CWE model considering arbitrary feed direction of tool path is proposed and the cutting force model is established by the mechanical method. Firstly, the vector of the feed path and normal vector of the sculptured surface are calculated from cutter location points (CLP). The machining coordinate system (MCS) is established to describe tool posture. The contact condition between the cutter and workpiece is analyzed to establish the boundary of CWE. In addition, the engage section of cutting edge is determined by plane projection of CWE and cutting edge. Finally, based on the classical oblique cutting theory and mechanical method, a prediction model of cutting force about sculptured surface machining is established. The innovations include the following: 
(1) A modeling method for the CWE of sculptured surface milling is proposed, which considers the tool axis vector and feed direction

(2) A projection dimensionality method is used to simplify the solving process of the instantaneous engage section between the cutting edge and the workpiece

(3) The parameterized expression of the undeformed chip thickness is improved, and it could be applied to the variable axis machining for the sculptured surface

The rest of the paper is organized as follows: in Section 2, the motion model of the tool is established and the MCS is defined. The CWE model is established in Section 3. The blade section of instantaneous engaging with the workpiece is obtained in Section 4. In Section 5, the cutting force model is established. A series of experiments is presented in Section 6 to verify the model. Finally, some conclusions are drawn in Section 7.

\section{Tool Motion State and Coordinate System}

The CWE and cutting edge could be expressed in different coordinate systems, respectively, but the intersection between them needs to be calculated in a same coordinate system. Therefore, a universal coordinate system transformation method is essential. In this paper, the vectors of tool and tool path are used to define the corresponding coordinate systems at each CLP. Also, the transformation relation is deduced between them for sculptured surface machining.

2.1. The Definition of Tool Posture. The position and orientation of the tool are determined in MCS. As shown in Figure 1, define the serial number of tool position in NC program as $i$, the instantaneous tool position as $P_{L(t)}$, the instantaneous tool contact point as $P_{C(t)}$, and the instantaneous unit vector of tool axis as $\mathbf{u}_{(t)}$ in MCS at time $t . P_{L(t)}$, $P_{C(t)}$, and $\mathbf{u}_{(t)}$ could be obtained by the interpolation of adjacent two tool positions as follows [4].

$$
\begin{aligned}
& P_{L(t)}=P_{L\left(t_{i}\right)}+\frac{t-t_{i}}{t_{i+1}-t_{i}}\left(P_{L\left(t_{i+1}\right)}-P_{L\left(t_{i}\right)}\right), \quad t \in\left[t_{i}, t_{i+1}\right], \\
& P_{C(t)}=P_{C\left(t_{i}\right)}+\frac{t-t_{i}}{t_{i+1}-t_{i}}\left(P_{L\left(t_{i+1}\right)}-P_{L\left(t_{i}\right)}\right), \quad t \in\left[t_{i}, t_{i+1}\right], \\
& \mathbf{u}_{(t)}=\frac{\mathbf{u}_{\left(t_{i}\right)}+\left(t-t_{i} / t_{i+1}-t_{i}\right)\left(\mathbf{u}_{\left(t_{i+1}\right)}-\mathbf{u}_{\left(t_{i}\right)}\right)}{\left|\mathbf{u}_{\left(t_{i}\right)}+\left(t-t_{i} / t_{i+1}-t_{i}\right)\left(\mathbf{u}_{\left(t_{i+1}\right)}-\mathbf{u}_{\left(t_{i}\right)}\right)\right|}, \quad t \in\left[t_{i}, t_{i+1}\right] .
\end{aligned}
$$

Define the instantaneous tool position unit feed vector as $\mathbf{v}_{(t)}$ at time $t$ in MCS, so

$$
\mathbf{v}_{(t)}=\frac{P_{L\left(t_{i+1}\right)}-P_{L\left(t_{i}\right)}}{\left|P_{L\left(t_{i+1}\right)}-P_{L\left(t_{i}\right)}\right|}, \quad t \in\left[t_{i}, t_{i+1}\right]
$$

2.2. The Definition of MCS. Define MCS as $O_{W}-X_{W} Y_{W} Z_{W}$, corresponding unit axis vector as $\mathbf{i}_{W}, \mathbf{j}_{W}$, and $\mathbf{k}_{W}$. The instantaneous milling coordinate system (IMCS) and instantaneous tool coordinate system (ITCS) are established to describe the contact relationship between the ball end mill and workpiece for sculptured surface machining, as shown in Figure 2.

2.2.1. IMCS. Define IMCS as $O_{M}-X_{M} Y_{M} Z_{M}$. The instantaneous tool position is set as the coordinate origin $O_{M}$. $X_{M}$ axis is parallel to the instantaneous feed vector $\mathbf{v}_{(t)}$, and $Z_{M}$ axis is parallel to the instantaneous normal vector $\mathbf{n}_{(t)}$ of the sculptured surface. Define the unit axis vector of IMCS as $\mathbf{i}_{M}$, $\mathbf{j}_{M}$, and $\mathbf{k}_{M}$.

$$
\left\{\begin{array}{l}
\mathbf{i}_{M}=\mathbf{v}_{(t)}, \\
\mathbf{j}_{M}=\mathbf{k}_{M} \times \mathbf{i}_{M}=n_{(t)} \times \mathbf{v}_{(t)}, \\
\mathbf{k}_{M}=\mathbf{n}_{(t)}, \\
\mathbf{n}_{(t)}=\frac{P_{L(t)}-P_{C(t)}}{\left|P_{L(t)}-P_{C(t)}\right|} .
\end{array}\right.
$$

2.2.2. ITCS. Define ITCS as $O_{T}-X_{T} Y_{T} Z_{T}$. Set the instantaneous tool position as coordinate origin $O_{T} . Z_{T}$ axis is parallel to the instantaneous tool axis vector $\mathbf{u}_{(t)}$, and $X_{T}$ axis is perpendicular to $Z_{M}$ and $Z_{T}$. Define the unit axis vector of ITCS as $\mathbf{i}_{T}, \mathbf{j}_{T}$, and $\mathbf{k}_{T}$.

$$
\left\{\begin{array}{l}
\mathbf{i}_{T}=\mathbf{k}_{M} \times \mathbf{k}_{T}=\mathbf{n}_{(t)} \times \mathbf{u}_{(t)}, \\
\mathbf{j}_{T}=\mathbf{k}_{T} \times \mathbf{i}_{T}=\mathbf{u}_{(t)} \times \mathbf{n}_{(t)} \times \mathbf{u}_{(t)}, \\
\mathbf{k}_{T}=\mathbf{u}_{(t)} .
\end{array}\right.
$$

\subsection{The Transformations of Coordinate Systems}

2.3.1. MCS to IMCS. The geometric relationship between IMCS and MCS is shown in Figure 3.

Define the angle between $Z_{M}$ and $Z_{W}$ as $\delta_{W M}$, the vector of the intersecting line of coordinate planes $X_{M} Y_{M}$ and $X_{W} Y_{W}$ as $\mathbf{s}$, the angle between $\boldsymbol{s}$ and $X_{W}$ as $\gamma_{W M}$, and the angle between $\mathbf{s}$ and $X_{M}$ as $\varepsilon_{W M}$. 


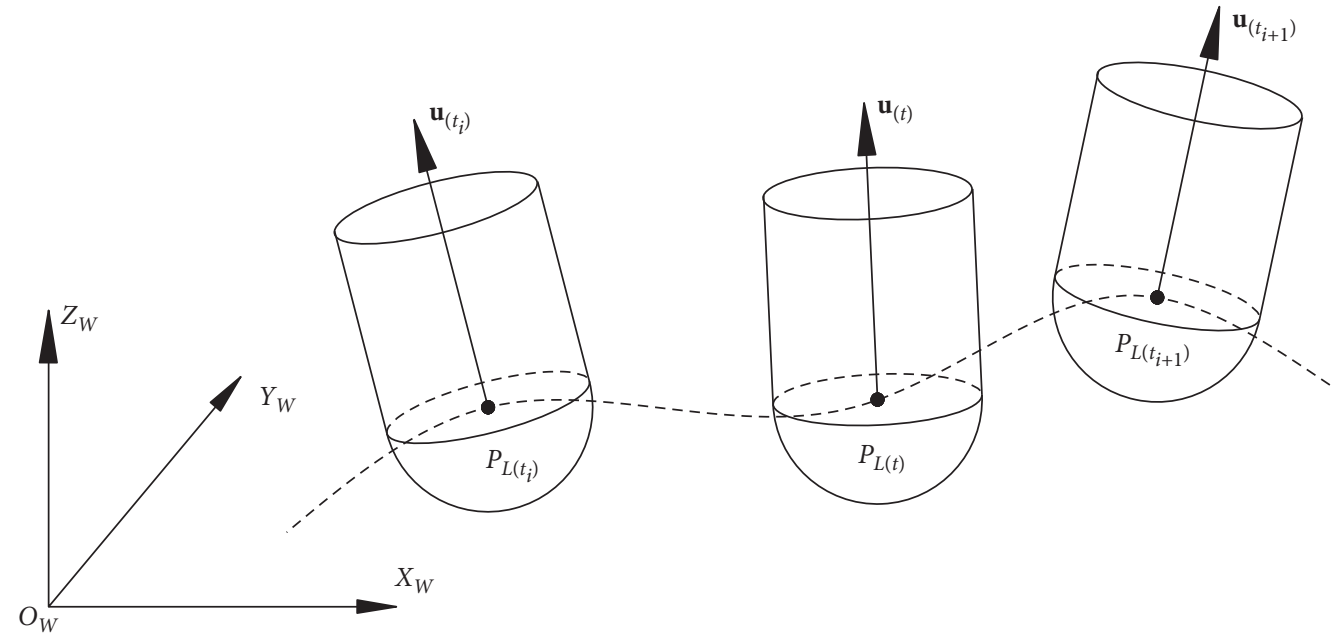

Figure 1: Instantaneous position and orientation of tool at time $t$.

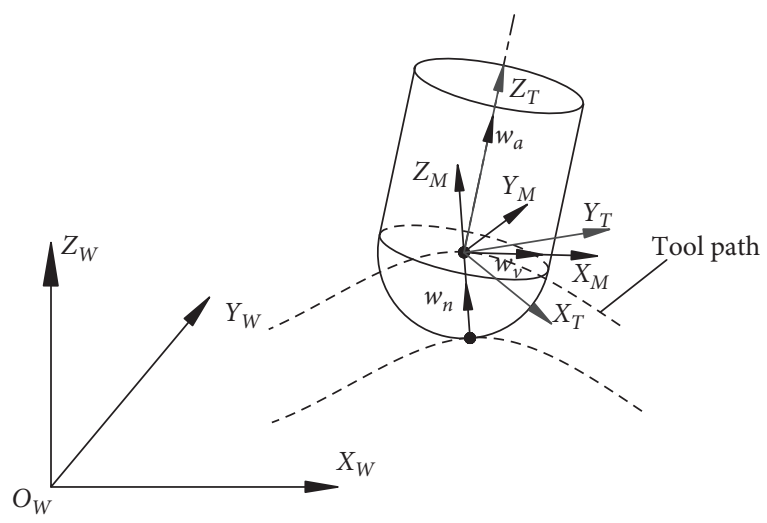

Figure 2: Schematic of instantaneous MCS, IMCS, and ITMCS.

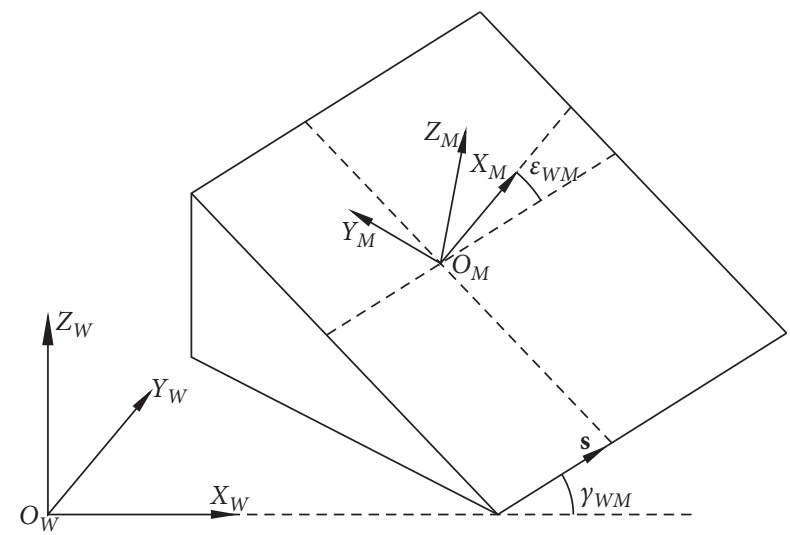

FIGURE 3: Geometric relationship between the instantaneous end mill coordinate system and MCS.

$$
\begin{aligned}
\delta_{W M} & =\arccos \left(\mathbf{k}_{W} \cdot \mathbf{k}_{M}\right), \\
\mathbf{s} & =\mathbf{k}_{W} \times \mathbf{k}_{M}, \\
\gamma_{W M} & =\arccos \left(\mathbf{s} \cdot \mathbf{i}_{W}\right), \\
\mathcal{E}_{W M} & =\arccos \left(\mathbf{i}_{M} \cdot \mathbf{s}\right) .
\end{aligned}
$$

Set the coordinates of instantaneous tool position in MCS as $P_{L(t)}(x, y, z)$, and then IMCS could be obtained from MCS with transformation matrixes:

$$
\begin{aligned}
\mathbf{M}_{W M}= & \mathbf{T}_{W M} \cdot \mathbf{R}_{Z}\left(\varepsilon_{W M}\right) \cdot \mathbf{R}_{X}\left(\delta_{W M}\right) \cdot \mathbf{R}_{Z}\left(\gamma_{W M}\right) \\
= & \left(\begin{array}{cccc}
1 & 0 & 0 & -x \\
0 & 1 & 0 & -y \\
0 & 0 & 1 & -z \\
0 & 0 & 0 & 1
\end{array}\right) \cdot\left(\begin{array}{ccccc}
\cos \varepsilon_{W M} & -\sin \varepsilon_{W M} & 0 & 0 \\
\sin \varepsilon_{W M} & \cos \varepsilon_{W M} & 0 & 0 \\
0 & 0 & 1 & 0 \\
0 & 0 & 0 & 1
\end{array}\right) \\
& \cdot\left(\begin{array}{cccc}
1 & 0 & \cos \delta_{W M} & 0 \\
0 & \cos \delta_{W M} & -\sin \delta_{W M} & 0 \\
0 & \sin \delta_{W M} & \cos \\
0 & 0 & 0 & 1
\end{array}\right) \\
& \cdot\left(\begin{array}{cccc}
\cos \gamma_{W M} & -\sin \gamma_{W M} & 0 & 0 \\
\sin \gamma_{W M} & \cos \gamma_{W M} & 0 & 0 \\
0 & 0 & 1 & 0 \\
0 & 0 & 0 & 1
\end{array}\right),
\end{aligned}
$$

where $\mathbf{T}_{W M}$ is the translation transfer matrix; $\mathbf{R}_{Z}\left(\varepsilon_{W M}\right)$ is the rotational transfer matrix around the $Z$-axis with angle $\varepsilon_{W M}$; $\mathbf{R}_{X}\left(\delta_{W M}\right)$ is the rotational transfer matrix around $X$-axis with angle $\delta_{W M} ; \mathbf{R}_{Z}\left(\gamma_{W M}\right)$ is the rotational transfer matrix around $Z$-axis with angle $\gamma_{W M}$.

2.3.2. IMCS to ITCS. According to the geometric relationship between ITCS and IMCS, the angle $\delta_{M T}$ between $Z_{T}$ and $Z_{M}$ and the angle $\gamma_{M T}$ between $X_{T}$ and $X_{M}$ could be obtained as follows:

$$
\begin{aligned}
& \delta_{M T}=\arccos \left(k_{M} \cdot k_{T}\right), \\
& \gamma_{M T}=\arccos \left(i_{M} \cdot i_{T}\right) .
\end{aligned}
$$


The transformation matrix $\mathbf{M}_{M T}$ from IMCS to ITCS could be expressed as follows:

$$
\begin{aligned}
\mathbf{M}_{M T}= & \mathbf{R}_{X}\left(\delta_{M T}\right) \cdot \mathbf{R}_{Z}\left(\gamma_{M T}\right)= \\
& \cdot\left(\begin{array}{cccc}
1 & 0 & 0 & 0 \\
0 & \cos \delta_{M T} & -\sin \delta_{M T} & 0 \\
0 & \sin \delta_{M T} & \cos \delta_{M T} & 0 \\
0 & 0 & 0 & 1
\end{array}\right) \\
& \cdot\left(\begin{array}{cccc}
\sin \gamma_{M T} & -\sin \gamma_{M T} & 0 & 0 \\
0 & 0 & 1 & 0 \\
0 & 0 & 0 & 1
\end{array}\right),
\end{aligned}
$$

where $\mathbf{R}_{X}\left(\delta_{M T}\right)$ is the rotational transfer matrix around the $X$-axis with $\delta_{M T} ; \mathbf{R}_{Z}\left(\gamma_{M T}\right)$ is the rotational transfer matrix around the $Z$-axis with $\gamma_{M T}$.

\section{The CWE Model of Ball End Milling}

The schematic of CWE in sculptured milling is shown in Figure 4, which is surrounded by three boundaries: the swept profile between the current tool path sweep surface and cutter revolution surface, the intersection of the previous adjacent tool path sweep surface and current cutter revolution surface, and the intersection of the tool revolution surface and unmachined surface.

3.1. The Swept Profile. The current machining surface is formed by cutter revolve sweeping along the current tool path. The swept profile is the tangent line between the cutter revolution surface and current machining surface, which is perpendicular to the tool path direction, as shown in Figure 5.

In IMCS, the swept profile could be expressed as follows:

$$
\left\{\begin{array}{l}
x_{M}=0, \\
y_{M}=R \cos \theta_{M}, \\
z_{M}=-R \sin \theta_{M},
\end{array}\right.
$$

where $\theta_{M}$ is the angle between the line connecting the origin of IMCS to any point on the swept profile and $Y_{M}$.

3.2. The Intersecting Line. As shown in Figure 6, the points, which are the intersection of the current cutter revolution surface and the swept profile on the previous adjacent tool path, form the intersecting line. Therefore, the intersecting line could be expressed by a series of discrete points.

In the current IMCS, the revolution surface of the cutter at the current CLP could be expressed as follows.

$$
x_{M}^{2}+y_{M}^{2}+z_{M}^{2}=R^{2} .
$$

The swept profile in the previous adjacent tool path could be expressed as follows.

$$
\left\{\begin{array}{l}
x_{M}^{\prime}=0, \\
y_{M}^{\prime}=R \cos \theta^{\prime}, \\
z_{M}^{\prime}=-R \sin \theta_{M}^{\prime} .
\end{array}\right.
$$

By MCS-IMCS transformation, the swept profile in the previous IMCS on the previous adjacent tool path could be transformed to the current IMCS.

$$
\left[\begin{array}{c}
x_{M} \\
y_{M} \\
z_{M} \\
1
\end{array}\right]=\mathbf{M}_{W M} \mathbf{M}_{W M}^{\prime}-1\left[\begin{array}{c}
x_{M}^{\prime} \\
y_{M}^{\prime} \\
z_{M}^{\prime} \\
1
\end{array}\right] .
$$

The one-dimensional nonlinear equation for $\theta^{\prime}{ }_{M}$ could be obtained from equations (10), (11), and (12). The numerical method (the Newton-Raphson method) could be applied to solve it. Then, the coordinates of intersection points in the current IMCS could be calculated.

3.3. The Surface Intersecting Line. There are many methods about the sculptured surface machining, such as multilayers cutting and single-layer cutting. They result in two cases of the unmachined surface, one is the previous machined surface and the other is the surface of workpiece blank. For the former, the surface intersecting line is formed by current cutter revolve and the previous machined surface, which can be solved in the same way in Section 3.2. However, because the tool paths in two cutting layers may be different, it is difficult to be solved. For the latter, the uncertain workpiece blank makes it difficult to describe the unmachined surface. In order to improve the calculation efficiency, an offset plane is defined to substitute the two types of unmachined surface. As shown in Figure 7, the unmachined surface is simplified as the plane that offset $a_{p}$ from the tangent plane at $P_{C(t) \text {. }}$

$$
\left\{\begin{array}{l}
x_{M}=\sqrt{R^{2}-\left(R-a_{p}\right)^{2}} \cos \varphi_{M}, \\
y_{M}=\sqrt{R^{2}-\left(R-a_{p}\right)^{2}} \sin \varphi_{M}, \\
z_{M}=a_{p}-R .
\end{array}\right.
$$

where $\varphi_{M}$ is the angle between the line (it connects the $Z_{M^{-}}$ axis to any point on the surface intersecting line) and $\mathbf{v}_{(\mathrm{t})}$.

3.4. The Verification of CWE. In order to verify the accuracy of the proposed CWE model, an experiment was carried out. The parameters of experiment are shown in Table 1, and the workpiece geometry and tool path are shown in Figure 8. The guiding line is an arc (radius is $208 \mathrm{~mm}$ ) located in the bottom plane of workpiece, and the workpiece entity is generated by the "scanning and mixing" instruction of PTC Creo. The tool path is the projection of the guiding line on the workpiece surface. The boundary of CWE is simulated by Matlab. Based on the Boolean operation function of PTC Creo, the solid model of CWE is established. The simulations of the two models are all performed on the same computer (Intel(R) Celeron(R) CPU G1840 @ 2.80 GHz, RAM 8 GB). 16 CLPs are selected equidistantly, and the shape and size of CWE obtained by two ways are almost the same.

Numerous literatures show that the solid model has very high accuracy. Therefore, the results of the solid model are 


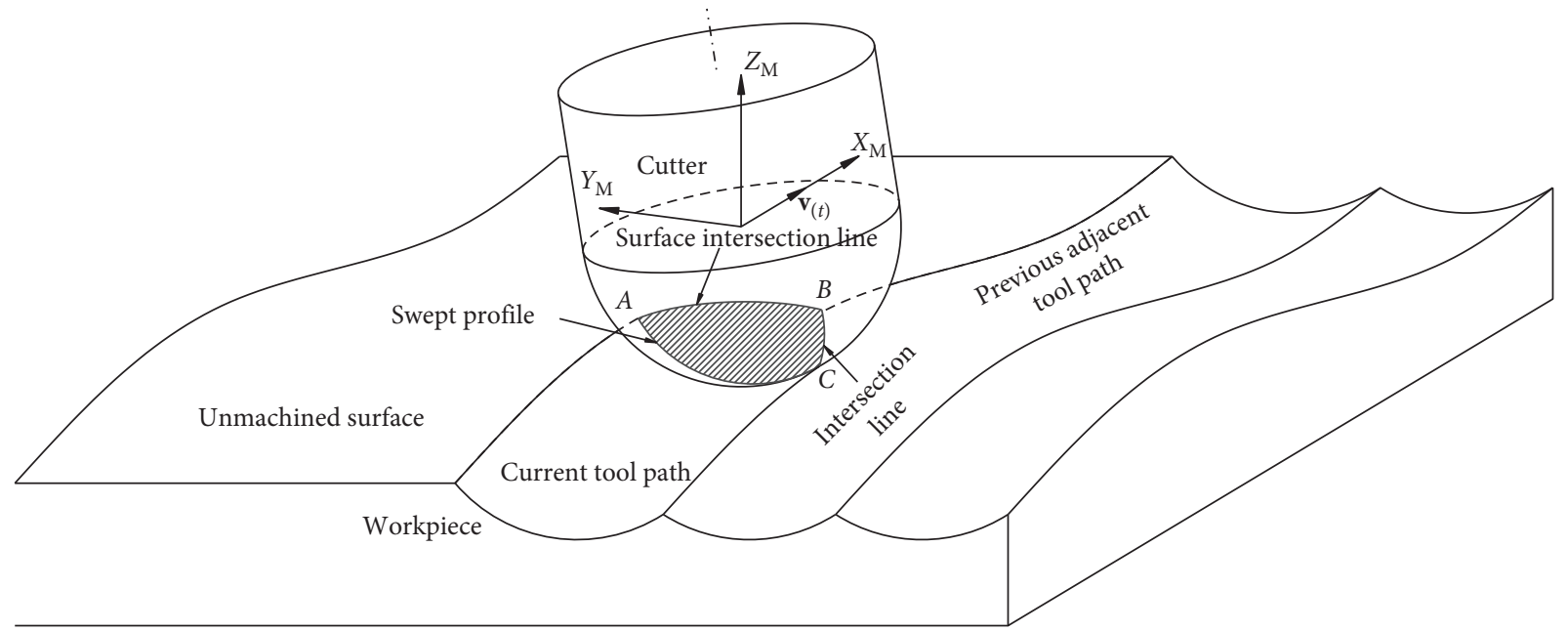

Figure 4: Schematic of CWE.

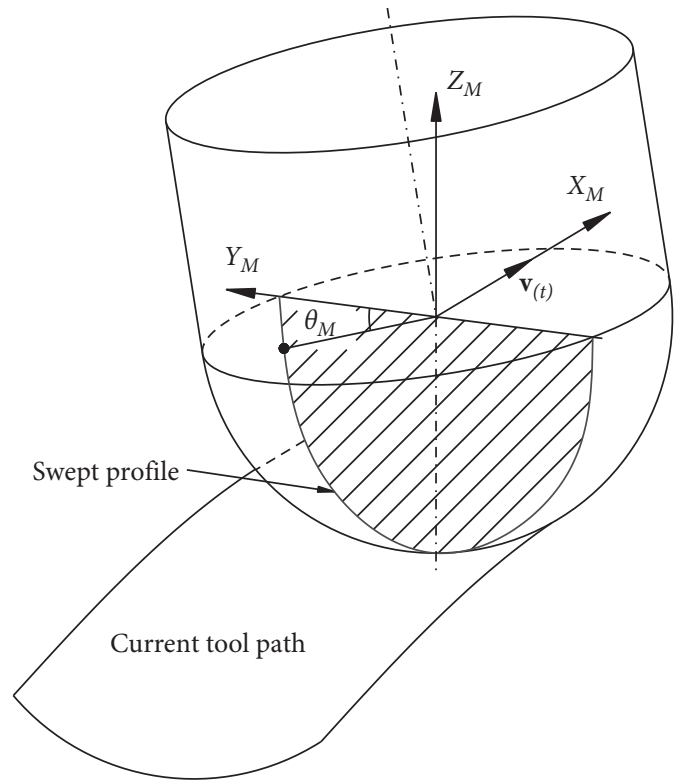

FIGURE 5: Schematic of swept profile.

used as the standard value to analyze the errors of the boundary model. In the solid model, the area of CWE can be extracted by the software directly. Also, in the boundary model, the area can be obtained by the Monte Carlo method. The errors of the boundary model at different CLPs are shown in Table 2, which are less than 3\%. The former takes approximately $75 \mathrm{~s}$ at each CLP, and the latter takes only $0.25 \mathrm{~s}$. The results show that the proposed boundary model has high computational efficiency and accuracy.

When solving the surface intersecting line of CWE, unmachined surface is simplified to a plane, which shows that the curvature of the workpiece surface has some influence on the accuracy of the boundary model. The accuracy is influenced by the curvature radius $r$ of the workpiece surface and the radius $R$ of ball end mill, as shown in Figure 9. When $R / r<0.12$, the error is within $5 \%$.

\section{The Engage Section of Cutting Edge in CWE}

In machining, only part of the blade can engage with the workpiece. Obtaining the instantaneous engage section of the cutting edge is critical for calculating the cutting force.

4.1. The Model of End Cutting Edge About the Ball End Mill. As shown in Figure 10, the center of the ball coincides with the origin of ITCS, and the tool axis coincides with $Z_{T}$. Define pitch helix on the cylindrical surface coaxial with $Z_{T}$ as guiding line that forms the cutting edge. The line $P_{G} Q$ is parallel to the coordinate plane $X_{T} Y_{T}$ ( $P_{G}$ is on the guiding line). The intersection $P$ of line $P_{G} Q$ and spherical surface is a point of the cutting edge.

Since the cutting edge is located on the spherical surface, the end cutting edge could be expressed as follows:

$$
\left\{\begin{array}{l}
x_{T}=R \cos \theta_{T} \cos \varphi_{T}, \\
y_{T}=R \cos \theta_{T} \sin \varphi_{T}, \\
z_{T}=-R \sin \theta_{T},
\end{array}\right.
$$

where $R$ is the radius of the ball end mill; $\theta_{T}$ is the axial position angle of the microedge; and $\varphi_{T}$ is the circumferential position angle of the microedge.

The circumferential starting angle $\varphi_{0}$ defines the starting point of the cutting edge. Define the circumferential angle of microelement relative to the starting point as the circumferential offset angle $\Delta \varphi_{T}$. The $\varphi_{T}$ could be expressed as follows:

$$
\varphi_{T}=\varphi_{0}-\Delta \varphi_{T}
$$

Since points $P$ and $P_{G}$ have the same coordinates in the $Z_{T}$-axis, then

$$
\Delta \varphi_{T}=\sin \theta_{T} \tan \beta_{G},
$$

where $\beta_{G}$ is the helical angle of the side cutting edge.

Therefore, the cutting edge could be represented by $\theta_{T}$. 


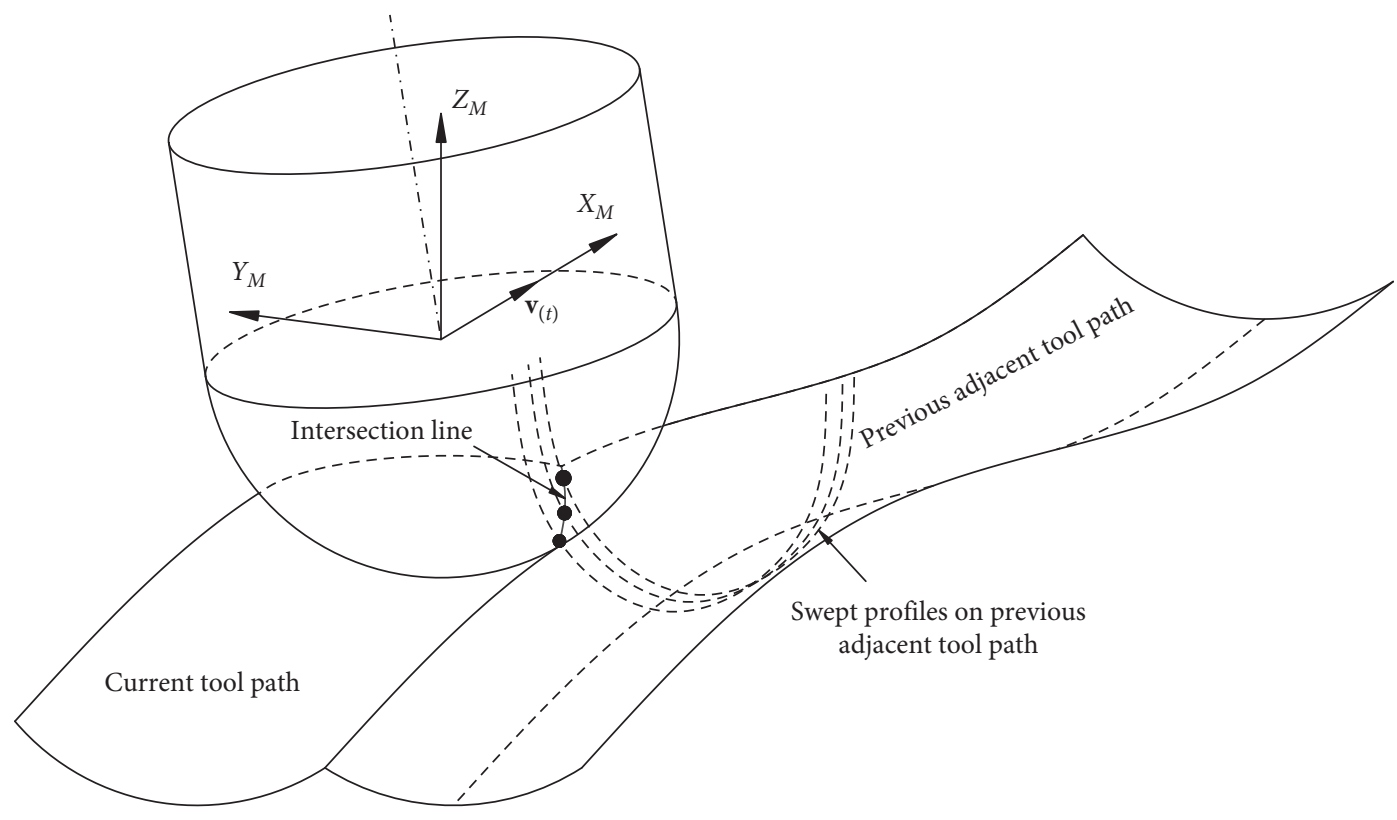

FIGURE 6: Schematic of intersection.

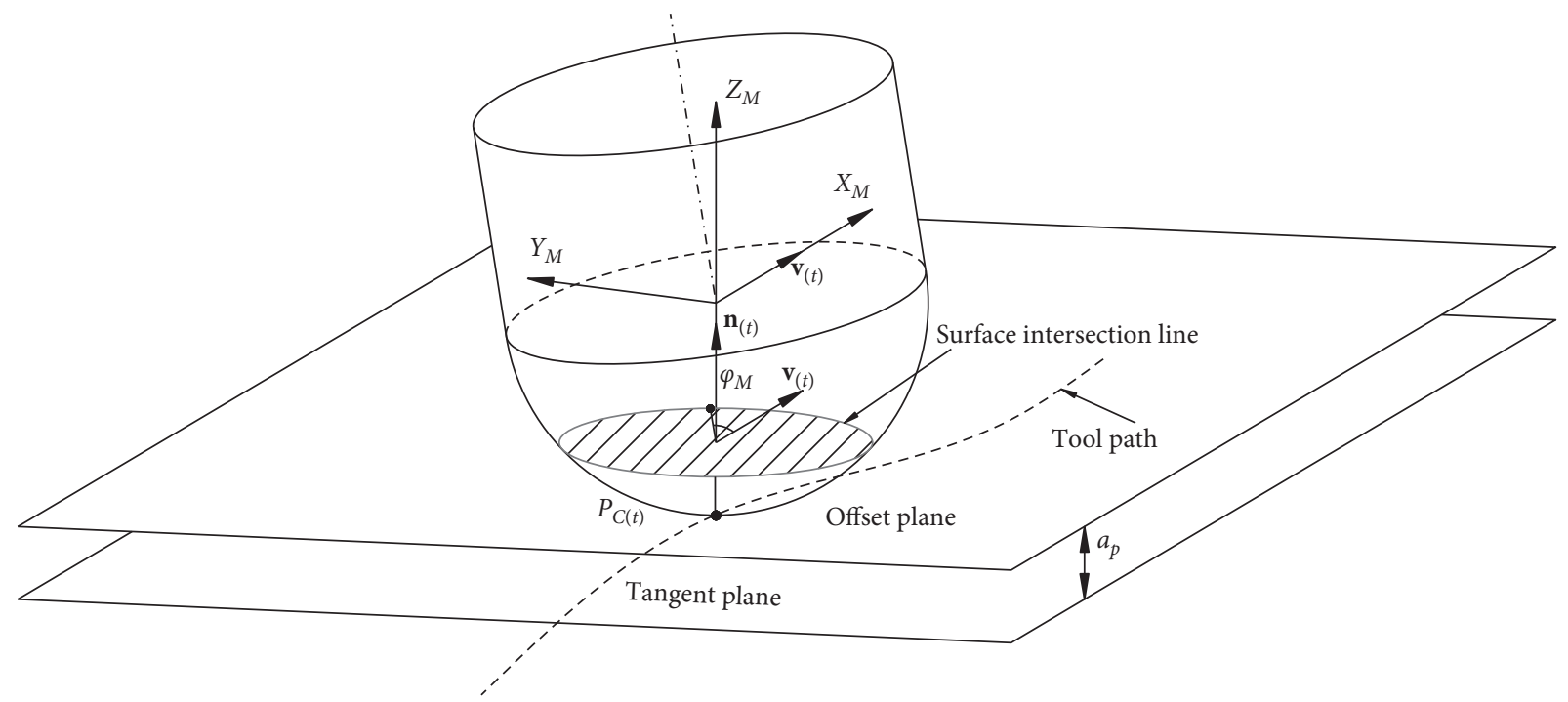

FIGURE 7: Schematic of surface intersecting line. The surface intersecting line in IMCS could be expressed as follows:

TABLE 1: The parameters of experiment.

\begin{tabular}{lcc}
\hline$R$ & $a_{p}$ & Stepover \\
\hline $3 \mathrm{~mm}$ & $0.8 \mathrm{~mm}$ & $1 \mathrm{~mm}$ \\
\hline
\end{tabular}

$$
\left\{\begin{array}{l}
x_{T}=R \cos \theta_{T} \cos \left(\varphi_{0}-\sin \theta_{T} \tan \beta_{G}\right), \\
y_{T}=R \cos \theta_{T} \sin \left(\varphi_{0}-\sin \theta_{T} \tan \beta_{G}\right), \\
z_{T}=-R \sin \theta_{T}
\end{array}\right.
$$

Some cutting edges do not cross the tool center at the apex. Define the distance from the edge to the center in the top view of the ball end mill as $h$, as shown in Figure 11.

For the cutting edge not passing the tool axis, the range of $\theta_{T}$ is within $[0, \arccos (h / R)]$. The result of the cutting edge is shown in Figure 12, and the cutting edge is in good agreement with the actual ball end mill. The parameters of the ball end mill are shown in Table 3 .

\subsection{The Engage Section}

4.2.1. Boundary Conditions of CWE. As shown in Figure 13, CWE is a closed local spherical area and intersects the cutting edge at two points. Both cutting edge and cutter turning surface have unique projection on the coordinate plane $X_{M} Y_{M}$ of IMCS. Thus, the intersection of CWE and cutting edge could be solved by projection.

From (9) and (13)fd13, the projection function $f_{\mathrm{SP}}$ of sweep profile and $f_{\text {SIL }}$ of surface intersecting line on the coordinate plane $X_{M} Y_{M}$ could be expressed as follows: 


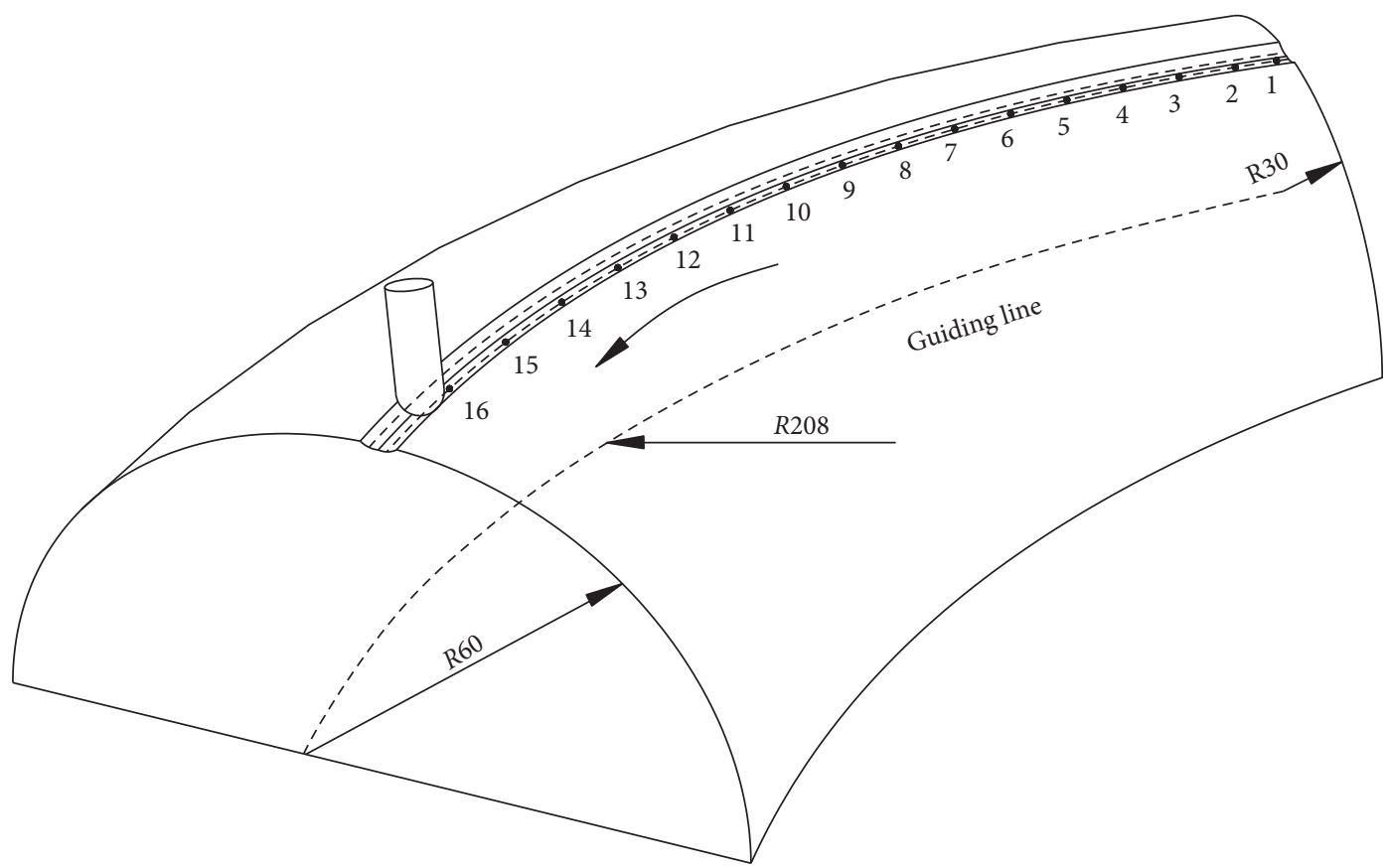

Figure 8: Schematic of simulation.

TABLE 2: Error analysis results of the boundary model.

\begin{tabular}{lccc}
\hline $\begin{array}{l}\text { Cutter } \\
\text { location } \\
\text { points }\end{array}$ & $\begin{array}{c}\text { Area of solid } \\
\text { model }\left(\mathrm{mm}^{2}\right)\end{array}$ & $\begin{array}{c}\text { Area of boundary } \\
\text { model }\left(\mathrm{mm}^{2}\right)\end{array}$ & $\begin{array}{c}\text { Area } \\
\text { error }(\%)\end{array}$ \\
\hline 1 & 3.33882 & 3.42771 & 2.59 \\
2 & 3.34437 & 3.42821 & 2.42 \\
3 & 3.34504 & 3.42780 & 2.40 \\
4 & 3.35209 & 3.43053 & 2.18 \\
5 & 3.35324 & 3.42855 & 2.15 \\
6 & 3.35889 & 3.43068 & 1.98 \\
7 & 3.35991 & 3.42924 & 1.94 \\
8 & 3.36711 & 3.43105 & 1.73 \\
9 & 3.37025 & 3.42983 & 1.63 \\
10 & 3.36896 & 3.43111 & 1.67 \\
11 & 3.37573 & 3.42884 & 1.47 \\
12 & 3.37878 & 3.43118 & 1.37 \\
13 & 3.3797 & 3.43036 & 1.35 \\
14 & 3.38268 & 3.43115 & 1.26 \\
15 & 3.38476 & 3.42797 & 1.20 \\
16 & 3.38861 & 3.42978 & 1.08 \\
\hline
\end{tabular}

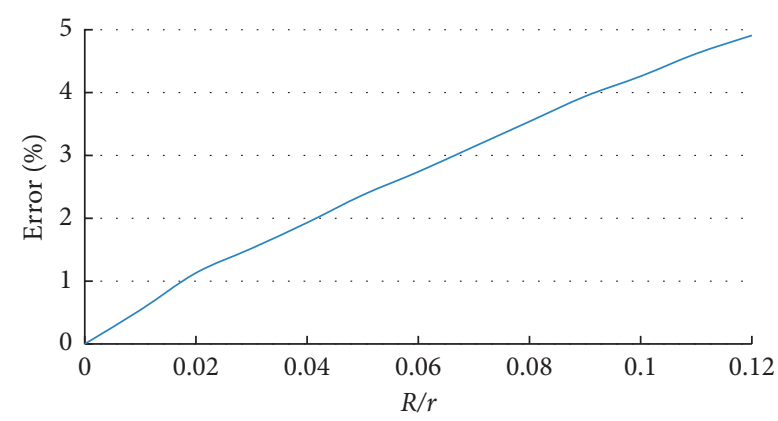

Figure 9: The error of the boundary model about (R)/(r).

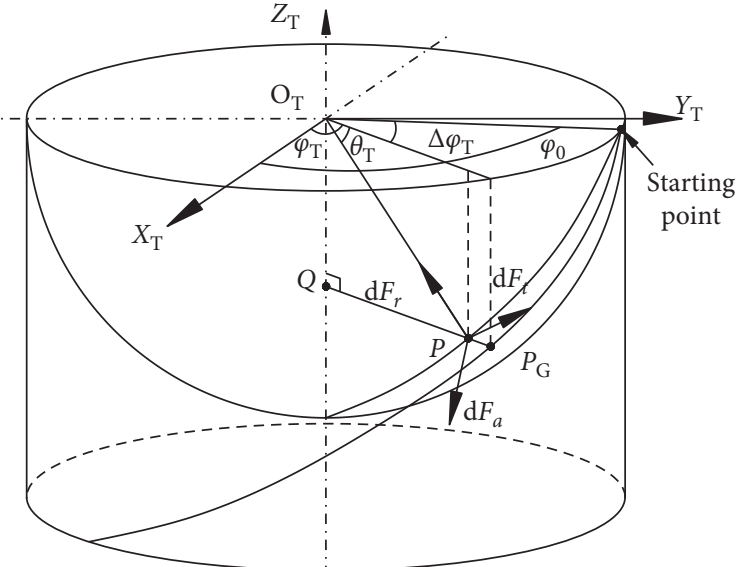

FIGURE 10: Schematic of the end cutting edge about the ball end mill.

$$
f_{\mathrm{SP}}\left(x_{M}, y_{M}\right)=x_{M}=0 \text {, }
$$

$$
f_{\mathrm{SIL}}\left(x_{M}, y_{M}\right)=x_{M}^{2}+y_{M}^{2}-\left[R^{2}-\left(R-a_{p}\right)^{2}\right]=0
$$

Also, the projection function $f_{\mathrm{IL}}$ of the intersecting line could be expressed as a polynomial, which could be obtained by fitting the discrete points on the intersection with the Newton interpolation method. Considering the stability and accuracy of interpolation, no more than 7 discrete points on the intersection are selected for fitting the curve. Also, the order of polynomial obtained by the Newton interpolation method is less than the number of interpolation nodes. The highest order polynomial could be expressed as follows: 




FIgURE 11: Schematic of the distance between the tooth and center.

$$
f_{\mathrm{IL}}\left(x_{M}, y_{M}\right)=\sum_{i=0}^{6} a_{i} \cdot x_{M}^{i}-y_{M}=0 .
$$

In summary, the cutting edge section that engages the workpiece should satisfy the following conditions:

$$
\left\{\begin{array}{l}
f_{\mathrm{SP}}\left(x_{M}, y_{M}\right) \geq 0, \\
f_{\mathrm{SIL}}\left(x_{M}, y_{M}\right) \leq 0, \\
f_{\mathrm{IL}}\left(x_{M}, y_{M}\right) \geq 0
\end{array}\right.
$$

4.2.2. Calculation of the Engage Section. The axial position angles at the intersection points of the CWE boundary and cutting edge are applied to indicate the engage section, which is in the range $\left(\theta_{T(s t)}, \theta_{T(\text { end })}\right)$. The steps are as follows:

Step 1: calculate the coordinates of all the microedges in ITCS by equation (17) with step $\Delta \theta_{T}$.

Step 2: transform the microedge coordinates from ITCS into IMCS by $\boldsymbol{M}_{M T}$

$$
\left(x_{M}, y_{M}, z_{M}, 1\right)^{T}=\mathbf{M}_{M T}^{-1}\left(x_{T}, y_{T}, z_{T}, 1\right)^{T} .
$$

Step 3: search the coordinates of microedges in IMCS base on the boundary condition equation (21). Moreover, find out the microedges which adjacent to the boundary of CWE (two adjacent microedges that are inside and outside CWE, respectively).

Step 4: search the microedges that are obtained in Step 3 with the dichotomy method, and find out the intersection of the CWE and cutting edge.

Step 5: calculate the axial position angles of the intersection points.

\section{The Prediction Model of Cutting Force}

5.1. The Cutting Force Model. According to the Armarego oblique angle microelement cutting force model [28], the cutting force of the microedge involved in CWE could be expressed as follows:

$$
\left\{\begin{array}{l}
\mathrm{d} F_{r}=K_{r c} t_{n} \mathrm{~d} b+K_{r e} \mathrm{~d} s, \\
\mathrm{~d} F_{a}=K_{a c} t_{n} \mathrm{~d} b+K_{a e} \mathrm{~d} s, \\
\mathrm{~d} F_{t}=K_{t c} t_{n} \mathrm{~d} b+K_{t e} \mathrm{~d} s,
\end{array}\right.
$$

where $\mathrm{d} F_{r}, \mathrm{~d} F_{a}$, and $\mathrm{d} F_{t}$ are the radial, axial, and tangential forces of the microedge cutting edge; $K_{r c}, K_{a c}$, and $K_{t c}$ are the shear coefficients; $K_{r e}, K_{a e}$, and $K_{t e}$ are the blade force coefficients; $t_{n}$ is the thickness of undeformed chip; $\mathrm{d} b$ is the projection width of the microedge on the generatrix; and $\mathrm{d} s$ is the projection length of the microedge on the generatrix.

5.2. The Calculation of Microedge. The width $\mathrm{d} b$ could be expressed by microaxial position angle $\mathrm{d} \theta_{T}$ and ball end mill radius $R$.

$$
\mathrm{d} b=R \mathrm{~d} \theta_{T} .
$$

The length $\mathrm{d} s$ could be solved by the arc length differential formula.

$$
\begin{aligned}
\mathrm{d} s & =\sqrt{x_{T}^{\prime 2}\left(\theta_{T}\right)+y_{T}^{\prime 2}\left(\theta_{T}\right)+z_{T}^{\prime 2}\left(\theta_{T}\right)} \cdot \mathrm{d} \theta_{T} \\
& =R \sqrt{1+\cos ^{4} \theta_{T} \tan ^{2} \beta_{G}} \cdot \mathrm{d} \theta_{T} .
\end{aligned}
$$

The thickness $t_{n}$ is a key parameter in the bevel cutting model, which is the projection of feed per tooth in the normal direction of the sphere [17]. The tool feed direction is consistent with the $X_{M^{-}}$axis of IMCS, and then the feed vector could be expressed as follows:

$$
\mathbf{v}_{M}=\left(f_{t}, 0,0\right)^{T},
$$

where $f_{t}$ is the feed per tooth.

Convert $\mathbf{v}_{M}$ to ITCS, then

$$
\mathbf{v}_{T}=\mathbf{M}_{M T} \cdot \mathbf{v}_{M},
$$

and the spherical normal vector of the end microedge could be expressed as follows:

$$
\mathbf{n}_{T}^{\prime}=\left(x_{T}, y_{T}, z_{T}\right)^{T} .
$$

The thickness $t_{n}$ could be solved as follows.

$$
t_{n}=\frac{\mathbf{v}_{T} \cdot \mathbf{n}_{T}}{\left|\mathbf{n}_{T}\right|}=\frac{\mathbf{v}_{T} \cdot \mathbf{n}_{T}}{R} .
$$

5.3. The Instantaneous Cutting Force. The cutting force of the microedge is not parallel to the axes of ITCS, which could be decomposed by the following equation: 

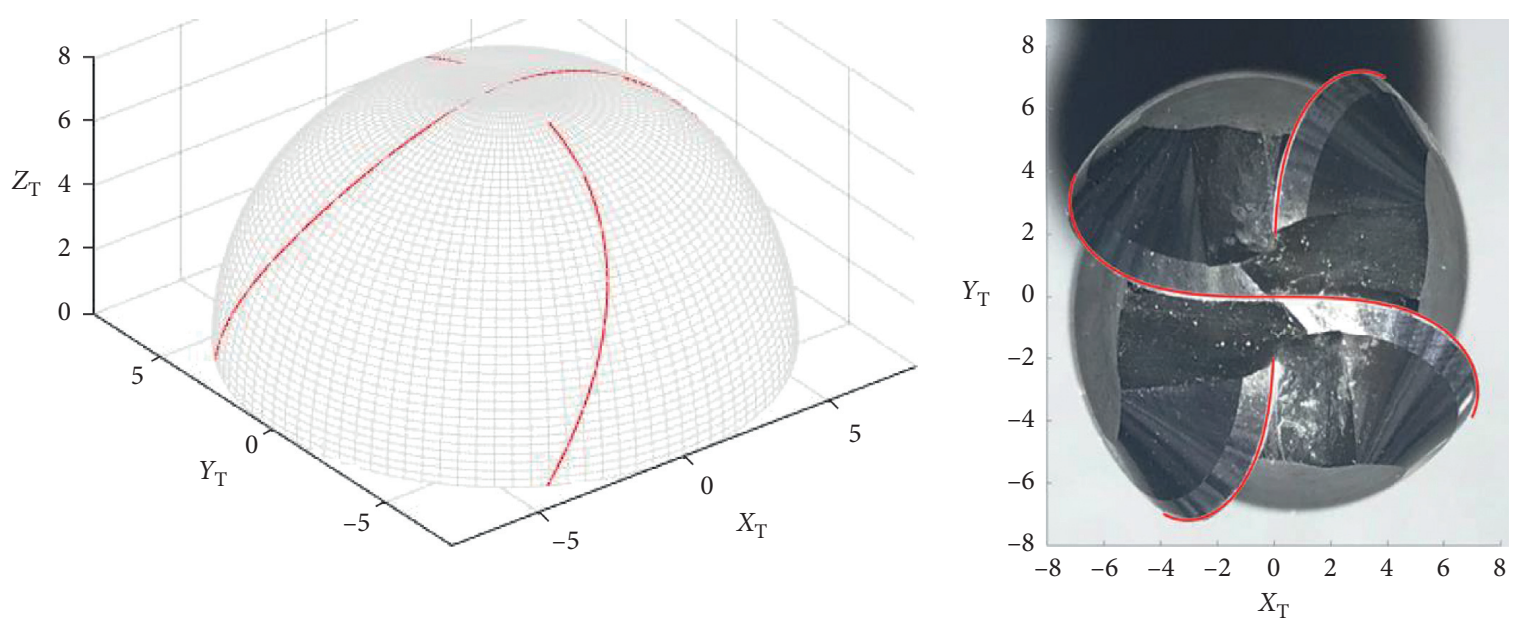

Figure 12: Example of a cutting edge.

TABLE 3: The parameters of a ball end mill.

\begin{tabular}{lccc}
\hline Tool radius $(R)$ & Number of teeth & Tooth offset $(h)$ & Tool helix angle $\left(\beta_{G}\right)$ \\
\hline $8 \mathrm{~mm}$ & 4 & $2 \mathrm{~mm}$ & $30^{\circ}$ \\
\hline
\end{tabular}

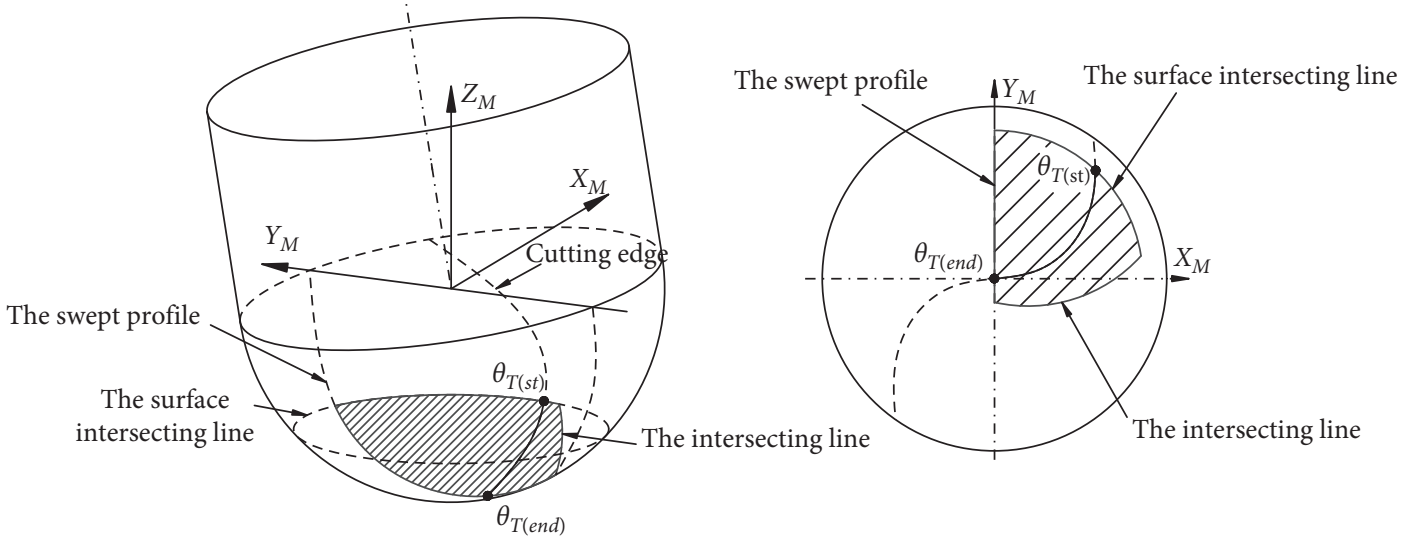

FIGURE 13: Schematic of CWE.

TABLE 4: The experiment parameters.

\begin{tabular}{lcccccc}
\hline Tool radius $(R)$ & Tool helix angle $\left(\beta_{G}\right)$ & Number of teeth & Depth of cut $\left(a_{p}\right)$ & Stepover & Feed speed & Spindle speed \\
\hline $6 \mathrm{~mm}$ & $30^{\circ}$ & 2 & $0.8 \mathrm{~mm}$ & $1 \mathrm{~mm}$ & $160 \mathrm{~mm} / \mathrm{min}$ & $500 \mathrm{r} / \mathrm{min}$ \\
\hline
\end{tabular}$$
\left[\begin{array}{c}
\mathrm{d} F_{x T} \\
\mathrm{~d} F_{y T} \\
\mathrm{~d} F_{z T} \\
0
\end{array}\right]=\left[\begin{array}{cccc}
-\cos \theta_{T} \cos \varphi_{T} & -\sin \theta_{T} \cos \varphi_{T} & \sin \varphi_{T} & 0 \\
-\cos \theta_{T} \sin \varphi_{T} & -\sin \theta_{T} \sin \varphi_{T} & -\cos \varphi_{T} & 0 \\
-\sin \theta_{T} & \cos \theta_{T} & 0 & 0 \\
0 & 0 & 0 & 1
\end{array}\right]\left[\begin{array}{c}
\mathrm{d} F_{r} \\
\mathrm{~d} F_{a} \\
\mathrm{~d} F_{t} \\
0
\end{array}\right],
$$

where $\mathrm{d} F_{x T}$ is the component of the microcutting force on the $X_{T}$ axis; $\mathrm{d} F_{y T}$ is the component of the microcutting force on the $Y_{T}$ axis; and $\mathrm{d} F_{z T}$ is the component of the microcutting force on the $Z_{T}$ axis.
Also, the instantaneous cutting force could be obtained as follows:

$$
\left\{\begin{array}{l}
F_{x T}=\int_{\theta_{T(s t)}}^{\theta_{T(\text { end })}} \mathrm{d} F_{x T}, \\
F_{y T}=\int_{\theta_{T(s t)}}^{\theta_{T(\text { end })}} \mathrm{d} F_{y T}, \\
F_{z T}=\int_{\theta_{T(\text { st })}}^{\theta_{T(\text { end })}} \mathrm{d} F_{z T},
\end{array}\right.
$$

where $F_{x T}$ is the component of the cutting force on the $X_{T}$-axis; $F_{y T}$ is the component of the cutting force on the $Y_{T}$-axis; and $F_{z T}$ is the component of the cutting force on the $Z_{T}$-axis. 
TABle 5: The data of tool path points at area A (part).

\begin{tabular}{lccccccccccc}
\hline CLP & \multicolumn{1}{c}{} & \multicolumn{4}{c}{ Tool axis vector $u_{(t)}$} & \multicolumn{3}{c}{ Feed vector $v_{(t)}$} & \multicolumn{3}{c}{ Normal vector $n_{(t)}$} \\
\hline$\ldots$ & $\ldots$ & $\ldots$ & $\ldots$ & $\ldots$ & $\ldots$ & $\ldots$ & $\ldots$ & $\ldots$ & $\ldots$ & $\ldots$ \\
164.378 & 5.837 & 64.303 & -0.902 & -0.034 & 0.428 & -0.963 & -0.035 & 0.265 & -0.428 & -0.015 & -0.903 \\
163.528 & 5.807 & 62.478 & -0.908 & -0.034 & 0.416 & -0.963 & -0.035 & 0.265 & -0.416 & -0.014 & -0.909 \\
162.702 & 5.778 & 60.642 & -0.913 & -0.034 & 0.404 & -0.963 & -0.035 & 0.265 & -0.404 & -0.014 & -0.914 \\
161.901 & 5.749 & 58.794 & -0.919 & -0.035 & 0.391 & -0.963 & -0.035 & 0.265 & -0.391 & -0.013 & -0.919 \\
161.124 & 5.722 & 56.937 & -0.924 & -0.035 & 0.379 & -0.963 & -0.035 & 0.265 & -0.379 & -0.013 & -0.925 \\
$\ldots$ & $\ldots$ & $\ldots$ & $\ldots$ & $\ldots$ & $\ldots$ & $\ldots$ & $\ldots$ & $\ldots$ & $\ldots$ & $\ldots$ & $\ldots$ \\
\hline
\end{tabular}

Table 6: The data of tool path points at area B (part).

\begin{tabular}{lccccccccccc}
\hline CLP & \multicolumn{9}{c}{} & \multicolumn{3}{c}{ Tool axis vector $u_{(t)}$} & \multicolumn{3}{c}{ Feed vector $v_{(t)}$} & \multicolumn{3}{c}{ Normal vector $n_{(t)}$} \\
\hline$\ldots$ & $\ldots$ & $\ldots$ & $\ldots$ & $\ldots$ & $\ldots$ & $\ldots$ & $\ldots$ & $\ldots$ & $\ldots$ & $\ldots$ \\
152.182 & 5.404 & 26.047 & -0.984 & -0.036 & 0.173 & -0.963 & -0.035 & 0.265 & -0.173 & -0.006 & -0.984 \\
151.846 & 5.392 & 24.061 & -0.986 & -0.036 & 0.160 & -0.963 & -0.035 & 0.265 & -0.160 & -0.005 & -0.987 \\
151.537 & 5.381 & 22.071 & -0.988 & -0.036 & 0.147 & -0.963 & -0.035 & 0.265 & -0.147 & -0.005 & -0.989 \\
151.254 & 5.371 & 20.077 & -0.990 & -0.036 & 0.133 & -0.963 & -0.035 & 0.265 & -0.133 & -0.004 & -0.991 \\
150.998 & 5.362 & 18.080 & -0.992 & -0.036 & 0.120 & -0.963 & -0.035 & 0.265 & -0.120 & -0.004 & -0.992 \\
$\ldots$ & $\ldots$ & $\ldots$ & $\ldots$ & $\ldots$ & $\ldots$ & $\ldots$ & $\ldots$ & $\ldots$ & $\ldots$ & $\ldots$ \\
\hline
\end{tabular}

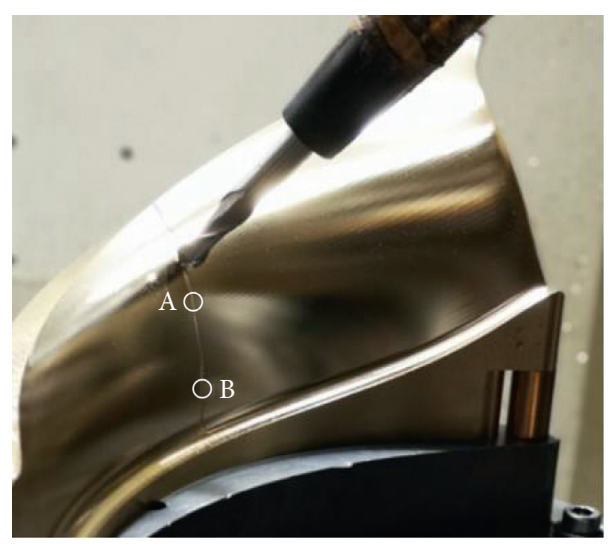

Figure 14: The scene of machining process.

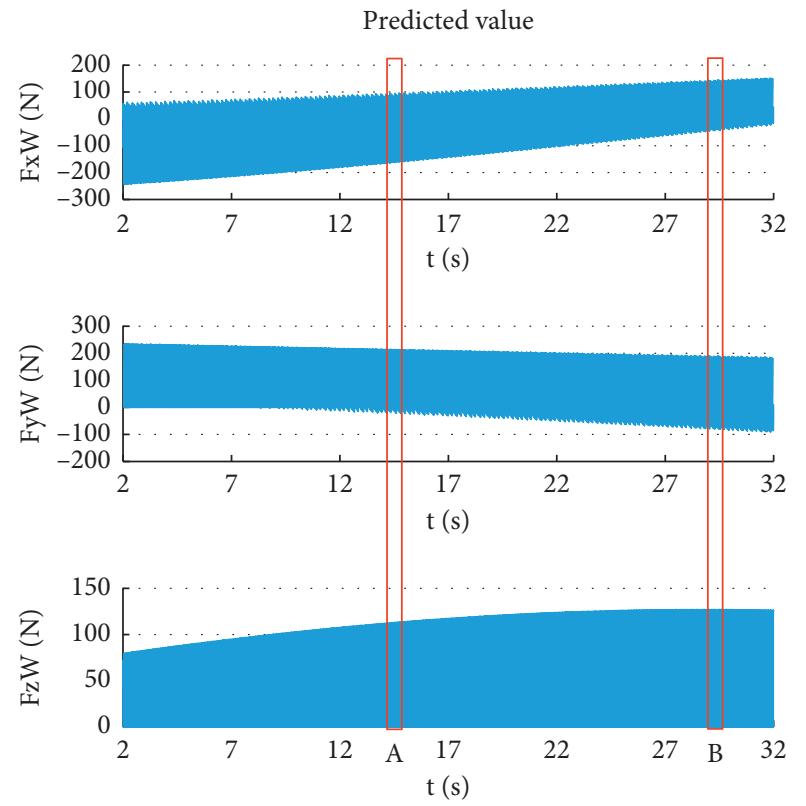

(a)

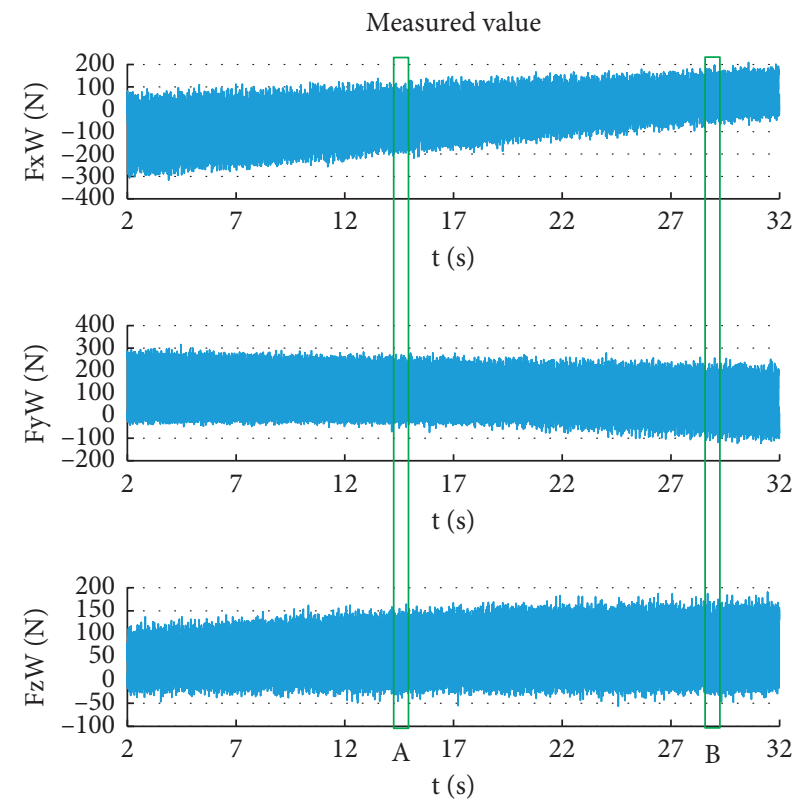

(b)

Figure 15: Comparison of measured cutting force and predicted cutting force (overall). (a) Measured cutting force. (b) Predicted cutting force. 

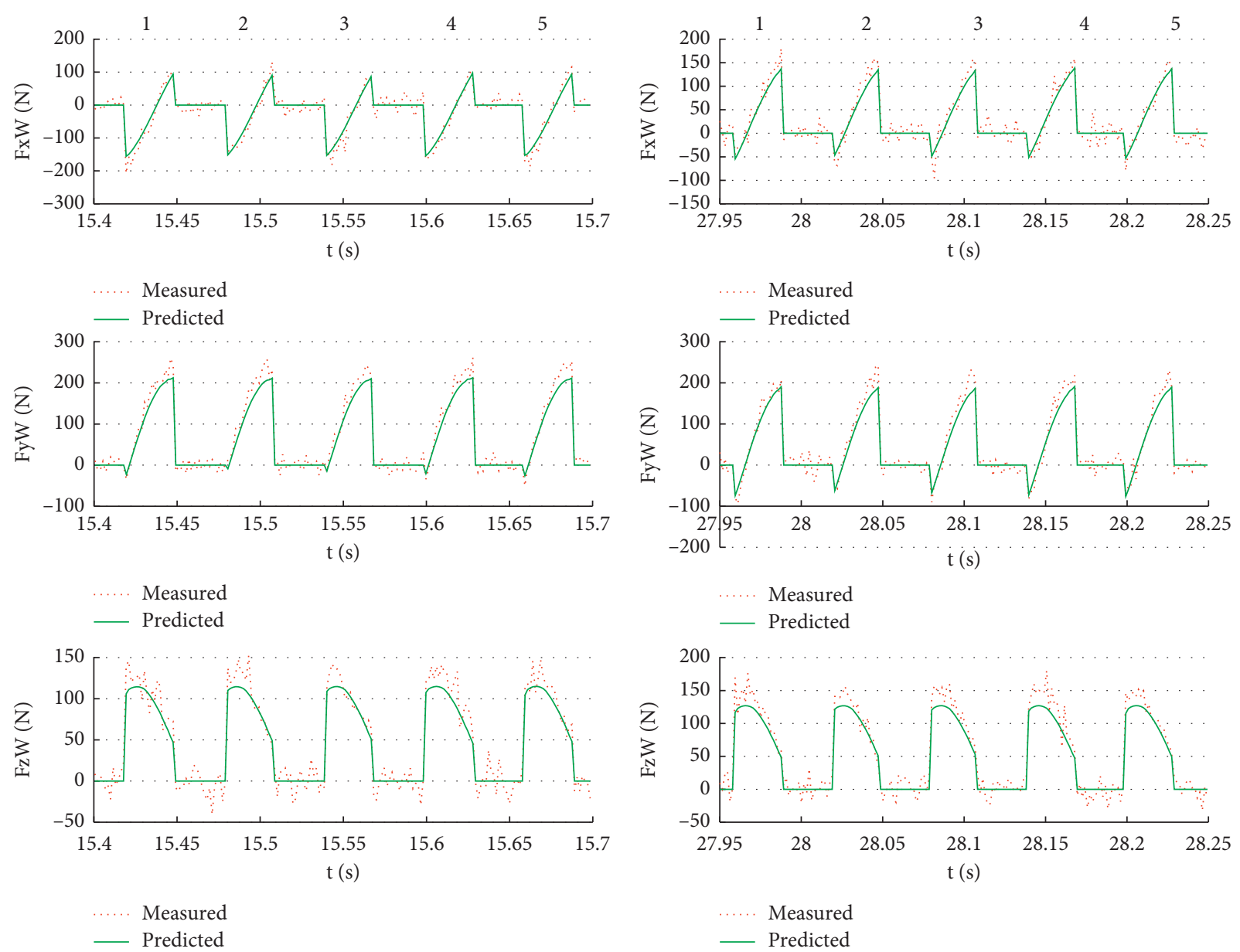

(a)

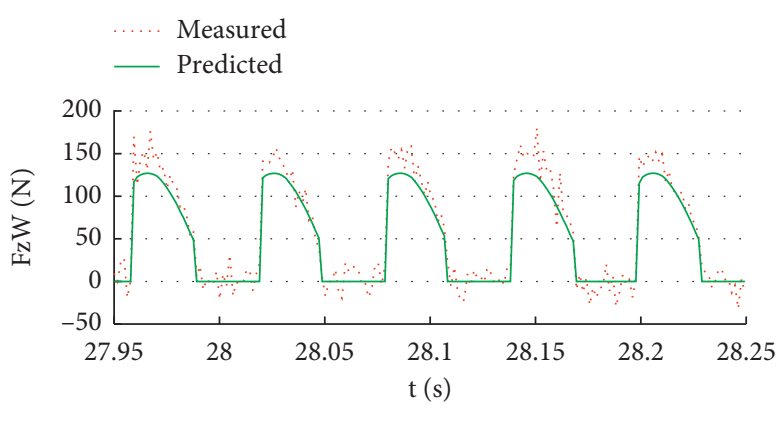

Measured
- Predicted

(b)

FIgURE 16: Comparisons of measured cutting force and predicted cutting force (part). (a) Comparison of cutting force details at area A. (b) Comparison of cutting force details at area $\mathrm{B}$.

TABLE 7: The errors of cutting force at area A and B.

\begin{tabular}{|c|c|c|c|c|c|c|c|}
\hline Area & Force & Peak error $1(\%)$ & Peak error $2(\%)$ & Peak error $3(\%)$ & Peak error $4(\%)$ & Peak error $5(\%)$ & Average error (\%) \\
\hline \multirow{3}{*}{ A } & $F_{\mathrm{xW}}$ & 14.56 & 6.99 & 15.87 & 7.32 & 18.37 & 8.51 \\
\hline & $F_{\mathrm{yW}}$ & 18.16 & 18.04 & 13.75 & 18.89 & 16.52 & 12.97 \\
\hline & $F_{\mathrm{zW}}$ & 14.72 & 16.62 & 15.64 & 11.50 & 9.66 & 6.32 \\
\hline \multirow{3}{*}{ B } & $F_{\mathrm{xW}}$ & 14.83 & 15.52 & 14.64 & 12.96 & 11.15 & 9.51 \\
\hline & $F_{\mathrm{yW}}$ & 12.50 & 15.63 & 12.03 & 12.33 & 18.24 & 12.55 \\
\hline & $F_{\mathrm{zW}}$ & 16.75 & 18.86 & 11.83 & 14.65 & 16.22 & 10.78 \\
\hline
\end{tabular}

\section{Verification of the Cutting Force Model}

In order to verify of cutting force model, a series of machining experiments for turbine blade were carried out with DMG DMU 100 mono Block five-axis machining tool. The workpiece material is copper alloy $\mathrm{ZCuAl} 8 \mathrm{Mn} 14 \mathrm{Fe} 3 \mathrm{Ni2}$ (tensile strength $\sigma_{b} \geq 645 \mathrm{MPa}$, yield strength $\sigma \geq 280 \mathrm{MPa}$ ). The tool is a carbide ball end mill. The experiment parameters are shown in Table 4 .

The force coefficients were identified by the methods proposed by Wojciechowski [29], which could be expressed as follows:

$$
\left\{\begin{array}{l}
K_{r c}=-5.787 \times 10^{4} \theta_{T}^{3}+1.895 \times 10^{4} \theta_{T}^{2}-2915 \theta_{T}+627.68, \\
K_{a c}=1.736 \times 10^{4} \theta_{T}^{3}+1.173 \times 10^{4} \theta_{T}^{2}-3745 \theta_{T}+374.34, \\
K_{t c}=-1.505 \times 10^{4} \theta_{T}^{3}+4.087 \times 10^{4} \theta_{T}^{2}-6769 \theta_{T}+1543.12, \\
K_{r e}=26.43 \mathrm{~N} / \mathrm{mm}, K_{a e}=13.52 \mathrm{~N} / \mathrm{mm}, K_{t e}=74.15 \mathrm{~N} / \mathrm{mm} .
\end{array}\right.
$$

Some CLPs, tool axis vectors, feed vectors, and normal vectors in MCS are shown in Tables 5 and 6 . The scene of machining process is shown in Figure 14.

The cutting force was acquired by a Kistler $9272 \mathrm{dy}$ namometer and $5070 \mathrm{~A}$ charge amplifier at $10 \mathrm{kHz}$. 
Combined with the calibration coefficients, cutting force was predicted by Matlab. The comparison results are shown in Figures 15 and 16. The trend of predicted value and the measured value has good consistency. Figure 16 shows that there is some noise in the measured data. Factors that may contribute to this effect include tool deformation, cutting vibration, and random measurement error of sensor. Table 7 shows that the errors of the predicted cutting force are less than $20 \%$. Considering the unstable cutting conditions, the errors are within the acceptable range.

\section{Conclusions}

(1) Based on the IMCS and ITCS, a motion model of the ball end mill for the sculptured surface is established. The motion state and the contact relationship between the cutter and workpiece could be described in a quantitative way.

(2) By solving three boundaries around the engagement of the cutter and workpiece, a CWE model is obtained. It has good adaptability for the variable tool axis relative to the machining surface.

(3) A prediction model of cutting force about ball end milling for a sculptured surface is constructed. It is suitable for sculptured surface machining with arbitrary tool posture and feed direction.

(4) The experiment results prove the effectiveness and validness of the proposed CWE model and cutting force prediction model.

\section{Notation}

$\begin{array}{lll} & & \mathrm{d} F_{y T}: \\ P_{L(t)}: & \text { Instantaneous tool position at time } t & \\ P_{C(t)}: & \text { Instantaneous tool contact point at time } t & \mathrm{~d} F_{z T}: \\ \mathbf{u}_{(t)}: & \text { Instantaneous unit vector of tool axis at time } t & \\ \mathbf{v}_{(t)}: & \text { Instantaneous tool position unit feed vector at } & F_{x T}: \\ & \begin{array}{l}\text { time } t \\ \mathbf{n}_{(t)}:\end{array} & \text { Instantaneous normal vector at time } t \\ i: & \text { Serial number of the tool position in the NC } & F_{y T}: \\ & \text { program } & F_{z T}: \\ t: & \text { Arbitrary time } & \\ t_{i}: & \text { Time of tool position } i \text { in NC program } & K_{r c}: \\ O_{W}: & \text { Machining coordinate system(MCS) } & K_{a c}: \\ X_{W} Y_{W} Z_{W}: & & K_{t c}: \\ O_{M}: & \text { Instantaneous milling coordinate } & K_{r e}: \\ X_{M} Y_{M} Z_{M}: & \text { system(IMCS) } & K_{a e}: \\ O_{T^{-}} X_{T} Y_{T} Z_{T}: & \text { Instantaneous tool coordinate system(ITCS) } & K_{t e}: \\ \mathbf{i}_{W}, \mathbf{j}_{W}, \mathbf{k}_{W}: & \text { Unit axis vector of MCS } & t_{n}: \\ \mathbf{i}_{M}, \mathbf{j}_{M}, \mathbf{k}_{M}: & \text { Unit axis vector of IMCS } & \mathrm{d} b: \\ \mathbf{i}_{T}, \mathbf{j}_{T}, \mathbf{k}_{T}: & \text { Unit axis vector of ITCS } & \mathrm{d} \theta_{T}: \\ \delta_{W M}: & \text { Angle between } Z_{M} \text { and } Z_{W} & \mathrm{~d} s: \\ \mathbf{s}: & \text { Vector of the intersection of coordinate planes } & v_{M}: \\ \gamma_{W M}: & X_{M} Y_{M} \text { and } X_{W} Y_{W} & f_{t}: \\ \varepsilon_{W M}: & \text { Angle between } s \text { and } X_{W} & v_{T}: \\ P_{L(t)}(x, y, z): & \text { Coordinate of the instantaneous tool position } & t_{\mathrm{n}}\left(\theta_{T}\right): \\ & \text { Angle between } s \text { and } X_{M} & \end{array}$

$\mathbf{M}_{W M}: \quad$ Transformation matrixes for MCS to IMCS T: $\mathbf{R}_{Z}$ :

$\mathbf{R}_{X}$ :

$\mathbf{M}_{M T}$ :

$\delta_{M T}:$

$\gamma_{M T}:$

$R:$

$\theta_{T}:$

$\varphi_{0}:$

$\varphi_{T}:$

$\Delta \varphi_{T}:$

$\beta_{G}$ :

$h$ :

$\theta_{M}$ :

$\theta^{\prime}{ }_{M}$ :

$P_{i}$ :

$N_{i, k}$ :

$\varphi_{M}:$

$\Delta \theta_{T}$ :

$\mathrm{d} F_{r}$ :

$\mathrm{d} F_{a}$ :

$\mathrm{d} F_{t}$ :

$\mathrm{d} F_{x T}$ :

$\mathrm{d} F_{y T}:$

$F_{z T}$ :

$F_{x T}$ :

$F_{y T}:$

$F_{z T}:$

$K_{r c}:$

$K_{a c}$ :

$K_{t c}$ :

$K$.

$K_{t e}:$

:

$\mathrm{d} b:$

$\mathrm{d} s$ :

$v_{M}$ :

$v_{T}:$

$t_{\mathrm{n}}\left(\theta_{T}\right): \quad$ Instantaneous undeformed chip thickness at $\theta_{T}$

Translation transfer matrix

Rotational transfer matrix around the $Z$-axis

Rotational transfer matrix around the $X$-axis Transformation matrixes for IMCS to ITCS Angle between $Z_{T}$ and $Z_{M}$

Angle between $X_{T}$ and $X_{M}$

Radius of the ball end mill

Axial position angle of the microedge

Circumferential starting angle

Circumferential position angle of the microedge

Circumferential offset angle

Helical angle of the side cutting edge

Distance of the tooth offset the center from the top view of the ball end mill

Angle between the line connecting the origin of IMCS to any point on the swept profile and $Y_{M}$

Angle between the line connecting the origin of previous IMCS to any point on the swept profile and $Y_{M}$

Characteristic point of the control curve $k$-order B-spline basis function

Angle between the line connecting the $Z_{M^{-}}$ axis to any point on the surface intersection and $v_{(\mathbf{t})}$

Axial position angle step size

Radial force of the microedge cutting edge Axial force of the microedge cutting edge Tangential force of the microedge cutting edge The component of the microcutting force on the $X_{T}$-axis of ITCS

The component of the microcutting force on the $Y_{T}$-axis of ITCS

The component of the microcutting force on the $Z_{T}$-axis of ITCS

The component of the cutting force on the $X_{T^{-}}$ axis of ITCS

The component of the cutting force on the $Y_{T^{-}}$ axis of ITCS

The component of the cutting force on the $Z_{T^{-}}$ axis of ITCS

Radial shear coefficients

Tangential shear coefficients

Radial blade force coefficients

Axial blade force coefficients

Tangential blade force coefficients

Thickness of undeformed chip

Width of the microedge

Axial position angle

Length of the microedge

Feed vector in IMCS

Feed per tooth

Feed vector in ITCS
Axial shear coefficients

in MCS 


\section{Data Availability}

The data used to support the findings of this study are available from the corresponding author upon request.

\section{Conflicts of Interest}

The authors declare that they have no conflicts of interest.

\section{Acknowledgments}

This work was supported by the Special Fund of High-end CNC Machine Tools and Basic Manufacturing Equipment (2017ZX04002001), China.

\section{References}

[1] M. Baburaj, A. Ghosh, and M. S. Shunmugam, "Development and experimental validation of a mechanistic model of cutting forces in micro- ball end milling of full slots," Machining Science and Technology, vol. 22, no. 5, pp. 787-810, 2018.

[2] A. Larue and Y. Altintas, "Simulation of flank milling processes," International Journal of Machine Tools and Manufacture, vol. 45, no. 4-5, pp. 549-559, 2005.

[3] G. G. Ju, Q. H. Song, and Z. Q. Liu, "Prediction of cutterworkpiece engagement for five-Axis ball-end milling," $M a$ terials Science Forum, Trans Tech Publications, vol. 800-801, pp. 254-258, 2014.

[4] Y. Yang, W. Zhang, M. Wan et al., "A solid trimming method to extract cutter-workpiece engagement maps for multi-axis milling," The International Journal of Advanced Manufacturing Technology, vol. 68, no. 9-12, pp. 2801-2813, 2013.

[5] X. Gong and H.-Y. Feng, "Cutter-workpiece engagement determination for general milling using triangle mesh modeling," Journal of Computational Design and Engineering, vol. 3, no. 2, pp. 151-160, 2016.

[6] Z. L. Li and L. M. Zhu, "An accurate method for determining cutter-workpiece engagements in five-axis milling with a general tool considering cutter runout," Journal of Manufacturing Science and Engineering, vol. 140, no. 2, Article ID 021001, 2018.

[7] G. M. Kim, P. J. Cho, and C. N. Chu, "Cutting force prediction of sculptured surface ball-end milling using Z-map," International Journal of Machine Tools and Manufacture, vol. 40, no. 2, pp. 277-291, 2000.

[8] I. Lazoglu, "Sculpture surface machining: a generalized model of ball-end milling force system," International Journal of Machine Tools and Manufacture, vol. 43, no. 5, pp. 453-462, 2003.

[9] G. Dongming, R. Fei, and S. Yuwen, "An approach to modeling cutting forces in five-axis ball end milling of curved geometries based on tool motion analysis," Journal of Manufacturing Science and Engineering, vol. 132, no. 4, Article ID 041004, 2010.

[10] Z. C. Wei, M. J. Wang, J. N. Zhu, and L. Y. Gu, "Cutting force prediction in ball end milling of sculptured surface with Z-level contouring tool path," International Journal of Machine Tools and Manufacture, vol. 51, no. 5, pp. 428-432, 2011.

[11] S. K. Gupta, S. K. Saini, B. W. Spranklin, and Z. Yao, "Geometric algorithms for computing cutter engagement functions in $2.5 \mathrm{D}$ milling operations," Computer-Aided Design, vol. 37, no. 14, pp. 1469-1480, 2005.
[12] B. Ozturk and I. Lazoglu, "Machining of free-form surfaces. part I: analytical chip load," International Journal of Machine Tools and Manufacture, vol. 46, no. 7-8, pp. 728-735, 2006.

[13] B. Ozturk, I. Lazoglu, and H. Erdim, "Machining of free-form surfaces. part II: calibration and forces," International Journal of Machine Tools and Manufacture, vol. 46, no. 7-8, pp. 736-746, 2006.

[14] Y. Sun and Q. Guo, "Numerical simulation and prediction of cutting forces in five-axis milling processes with cutter runout," International Journal of Machine Tools and Manufacture, vol. 51, no. 10-11, pp. 806-815, 2011.

[15] G. Kiswanto, H. Hendriko, and E. Duc, "An analytical method for obtaining cutter workpiece engagement during a semifinish in five-axis milling," Computer-Aided Design, vol. 55, pp. 81-93, 2014.

[16] Z. C. Wei, M. L. Guo, M. J. Wang et al., "Force predictive model for five-axis ball end milling of sculptured surface," The International Journal of Advanced Manufacturing Technology, vol. 98, no. 5-8, pp. 1367-1377, 2018.

[17] Z. C. Wei, M. L. Guo, M. J. Wang et al., "Prediction of cutting force for ball end mill in sculptured surface based on analytic model of CWE and ICCE," Machining Science and Technology, vol. 23, no. 5, pp. 688-711, 2019.

[18] Z. Zhu, F. Peng, R. Yan et al., "High efficiency simulation of five-axis cutting force based on the symbolically solvable cutting contact boundary model," The International Journal of Advanced Manufacturing Technology, vol. 94, no. 5-8, pp. 2435-2455, 2018.

[19] M. E. Merchant, "Basic mechanics of the metal cutting process," Journal of Applied Mechanics, vol. 11, no. A, pp. $168-175,1944$.

[20] E. H. Lee and B. W. Shaffer, "Theory of plasticity applied to the problem of machining," Journal of Applied Mechanics, vol. 18, pp. 405-413, 1951.

[21] P. L. B. Oxley, A. G. Humphreys, and A. Larizadeh, "The influence of rate of strain-hardening in machining," Proceedings of the Institution of Mechanical Engineers, vol. 175, no. 1, pp. 881-891, 1961.

[22] A. Moufik, D. Dudzinski, and A. Molinari, "Thermoviscoplastic modelling of oblique cutting: forces and chip flow predictions," International Journal of Mechanical Sciences, vol. 42, no. 6, pp. 1205-1232, 2000.

[23] A. Lamikiz, L. N. Lopez De Lacalle, J. A. Sanchez, and U. Bravo, "Calculation of the specific cutting coefficients and geometrical aspects in sculptured surface machining," $M a$ chining Science and Technology, vol. 9, no. 3, pp. 411-436, 2005.

[24] P. Lee and Y. Altintaş, "Prediction of ball-end milling forces from orthogonal cutting data," International Journal of Machine Tools and Manufacture, vol. 36, no. 9, pp. 1059-1072, 1996.

[25] Q. Cao, J. Zhao, S. Han, and X. Chen, "Force coefficients identification considering inclination angle for ball-end finish milling," Precision Engineering, vol. 36, no. 2, pp. 252-260, 2012.

[26] Z. W. Luo, W. X. Zhao, L. Jiao et al., "Cutting force prediction in end milling of curved surfaces based on oblique cutting model," The International Journal of Advanced Manufacturing Technology, vol. 89, no. 1-4, pp. 1025-1038, 2017.

[27] X. Lin, G. Wu, Y. Zhang et al., "The identification of the cutting force coefficients for ball end finish milling," The International Journal of Advanced Manufacturing Technology, vol. 102, no. 9-12, pp. 4121-4135, 2019. 
[28] E. J. A. Armarego and R. H. Brown, The machining of metals, 437 pages, Prentice-Hall, Englewood Cliffs, NJ, USA, 1969.

[29] S. Wojciechowski, "The estimation of cutting forces and specific force coefficients during finishing ball end milling of inclined surfaces," International Journal of Machine Tools and Manufacture, vol. 89, pp. 110-123, 2015. 